\title{
Degradabilidade in situ e parâmetros ruminais em bovinos alimentados com dietas balanceadas para diferentes ganhos de peso e potenciais de fermentação microbiana ${ }^{1}$
}

\author{
Rodolfo Marques de Brito ${ }^{2}$, Alexandre Amstalden Moraes Sampaio ${ }^{3}$, Alexandre Rodrigo \\ Mendes Fernandes ${ }^{4}$, Wignez Henrique ${ }^{5}$, José Wanderley Cattelan ${ }^{6}$, Karina de Souza Routman ${ }^{7}$ \\ 1 Parte da tese do primeiro autor apresentada à FCAV/Unesp/Jaboticabal. \\ 2 Unirp, São José do Rio Preto, SP. \\ ${ }^{3}$ Depto. Zootecnia/FCAV/UNESP, Jaboticabal, SP. Bolsista CNPq. \\ ${ }^{4}$ Pos-doutorando pela FCAV/Unesp/Jaboticabal. \\ ${ }^{5}$ Apta Regional, São José do Rio Preto, SP. \\ ${ }^{6}$ Depto. de Clínica e Cirurgia Veterinária/FCAV/Unesp, Jaboticabal, SP. \\ ${ }^{7}$ Mestre pela FCAV/Unesp/Jaboticabal.
}

RESUMO - Um experimento foi realizado com o objetivo de avaliar os parâmetros ruminais, a produção de ácidos graxos voláteis e a degradabilidade in situ em tourinhos Santa Gertrudes canulados no rúmen alimentados com dietas compostas de feno de capim-marandu e concentrado. Empregou-se o delineamento em quadrado latino $4 \times 4$, no qual os tratamentos foram compostos dos concentrados, ajustados para ganho de peso corporal (GPC) diário de 0,5 e $1 \mathrm{~kg} / \mathrm{animal}$ e potencial de fermentação microbiana (y) de 9,5 e 11 g de proteína bruta microbiana/MJ energia metabolizável fermentável. Não foram encontradas interações significativas nem diferenças entre as dietas para pH, concentração molar dos ácidos acético e butírico e proporção molar dos ácidos acético, propiônico e butírico e relação acético:propiônico. Os teores de amônia diferiram entre os potenciais de fermentação microbiana, 14,67 e 20,83 mg/100 mL para baixo e alto, respectivamente, e a concentração molar de ácido propiônico foi diferente entre os potenciais de ganho de peso, 7,62 e 8,94 mM, respectivamente, para baixo e alto ganho de peso. Não foram detectadas diferenças entre dietas para as degradabilidades das frações do feno de capim-marandu e da soja em grão. Houve diferença no parâmetro "b” e na degradabilidade efetiva a 5\%/hora da proteína bruta para os potencias de GPC do milho em grão moído. Para o farelo de soja, ocorreu interação significativa entre os potencias de GPC e de fermentação microbiana para alguns dos parâmetros da MS e PB, o mesmo observado para o farelo de algodão. As diferenças encontradas não justificaram o balanceamento dos concentrados para os diferentes potenciais de produção avaliados.

Palavras-chave: farelo de algodão, farelo de soja, milho em grão, potencial de ganho de peso, potencial de síntese microbiana, soja em grão

\section{In situ degradability and ruminal parameters by bovines fed diets balanced for different weight gains and potential of microbial fermentation}

\begin{abstract}
The experiment was carried out with the objective to evaluate the ruminal parameters, volatile fatty acids production and in situ degradability of Santa Gertrudis young bulls, canulated in the rumen, fed diets with palisadegrass hay and concentrates. A 4 × 4 latin square design was used, in which the treatments were composed by the concentrates, adjusted for daily body weight gain (BWG) of 0.5 and $1 \mathrm{~kg} /$ animal and potential microbial fermentation (y) of 9.5 and $11 \mathrm{~g}$ microbial crude protein/MJ fermentable metabolizable energy. No differences were observed for $\mathrm{pH}$, molar concentration of acetic and butyric acids, molar proportion of acetic, propionic and butyric acids and acetic:propionic ratio. There were differences between diets for the different potential microbial fermentations for ammonia level, 14.67 and $20.83 \mathrm{mg} / 100 \mathrm{~mL}$ for low and high, respectively, and for molar concentration of propionic acid, differed between the different potentials for weight gain, 7.62 and $8.94 \mathrm{mM}$, respectively, for low and high weight gain. There were no differences among diets for the degradability fractions of palisedagrass hay and soybean grain. There were difference in parameter "b" and effective degradability at 5\%/hour of CP for the potential BWG of corn grain. There was significant interaction between potential BWG and potential microbial fermentation for some parameters of DM and CP of soybean meal, the same was observed for cottonseed meal. The observe differences did not justify the the concentrate balance for the different evaluated production potential.
\end{abstract}

Key Words: corn grain, cottonseed meal, potential of bodyweight gain, potential of microbial fermentation, soybean grain, soybean meal 


\section{Introdução}

A criação de bovinos de corte no Brasil é feita em grande parte em condições de pastagem. As condições tropicais determinam períodos com diferenças acentuadas de produtividade e qualidade da forragem disponível para os animais no decorrer do ano. No intuito de manter o desempenho animal em níveis satisfatórios, tem sido largamente utilizada a suplementação alimentar, especialmente durante o período de escassez de forragem.

O tipo de suplemento a ser utilizado para manter o aporte de nutrientes para os animais é objeto de várias pesquisas. Muitos aspectos precisam ser estudados na avaliação desses suplementos, entre eles, as medidas tomadas no rúmen. Os principais parâmetros avaliados nesse compartimento são o pH, as concentrações de amônia $\left(\mathrm{NH}_{3}\right)$ e ácidos graxos voláteis (AGV), a temperatura, a pressão osmótica e o potencial de oxi-redução, que controlam as variações na taxa de crescimento dos microrganismos, em razão do nível, do tipo e da quantidade de substrato disponível e, portanto, diferenciam os nutrientes disponibilizados para os ruminantes.

Na maioria dos casos, o $\mathrm{pH}$ do líquido ruminal pode oscilar de 5,5 a 7,5, de acordo com a dieta. Fox et al. (1992) citaram o pH 6,46 como ótimo para síntese microbiana, com prejuízo severo à degradação de parede celular pelas bactérias fibrolíticas quando diminui abaixo de 5,43.

A concentração de $\mathrm{NH}_{3}$ no líquido ruminal é reguladora de vários processos de fermentação ruminal e esse valor está sujeito a ampla variação, conforme relatos de Vilela et al. (1994) de que a concentração de $\mathrm{NH}_{3}$ ruminal apresentou diferenças de até 99\% entre dietas com mesmo nível de concentrado. Mehrez \& Ørskov (1977) relataram que a concentração de $\mathrm{NH}_{3}$ de $23 \mathrm{mg} / 100 \mathrm{~mL}$ de líquido de rúmen seria ótima para obter a máxima taxa de fermentação. Para alimentos com maior conteúdo de parede celular, no entanto, Preston, citado por Queiroz et al. (1998), sugeriu concentração mínima de $20 \mathrm{mg} / 100 \mathrm{~mL}$.

Os AGV são a fonte de energia primária para o ruminante e suprem até $70 \%$ da demanda energética do animal. Como produtos finais do processo de multiplicação dos microrganismos ruminais, os AGV estão diretamente relacionados às condições de fermentação no rúmen e participam do controle do ambiente ruminal (Van Soest, 1982). Brito (2000) avaliou o comportamento dos AGV do rúmen em bovinos canulados alimentados com dietas contendo 20, 40 e 50\% de concentrado na MS e registrou como única diferença a proporção de ácido propiônico na dieta com $50 \%$ de concentrado.
Além dessas medidas tomadas no rúmen, outros fatores afetam o processo de aproveitamento dos alimentos pelos ruminantes. Mehrez \& Ørskov (1977) consideraram a degradabilidade das diversas frações dos alimentos e aperfeiçoaram a técnica da degradação in situ, que tem sido empregada e estudada intensivamente nos últimos 25 anos com os objetivos de comparar os alimentos e melhorar a compreensão do processo fermentativo. Ørskov \& McDonald (1979) introduziram o efeito da taxa de passagem na avaliação da degradabilidade e estabeleceram o conceito de degradação efetiva. Esses parâmetros foram integrados na avaliação de dietas pelo Agricultural Research Council (ARC, 1984) e pelo National Research Council (NRC, 1984).

Objetivou-se neste estudo avaliar os parâmetros ruminais, a produção de AGV e a degradabilidade dos nutrientes em tourinhos da raça Santa Gertrudes alimentados com dietas com feno de capim-marandu e concentrados, balanceadas para proporcionar dois níveis de ganho de peso associados a dois potenciais de síntese microbiana.

\section{Material e Métodos}

O ensaio foi conduzido no Setor de Bovinocultura de Corte e no Laboratório de Ruminantes na Faculdade de Ciências Agrárias e Veterinárias - Unesp, em Jaboticabal, SP. A altitude local é de 595 m e o clima, segundo classificação de Köppen, é do tipo subtropical, com chuvas de verão e inverno relativamente seco. As médias anuais de precipitação pluviométrica, temperatura e umidade relativa do ar registradas foram $1.400 \mathrm{~mm}, 21^{\circ} \mathrm{C}$ e $70 \%$, respectivamente.

A pastagem de capim-marandu (Brachiaria brizantha cv. Marandu ) selecionada para confecção do feno utilizado nas dietas foi mantida sob pastejo durante o período chuvoso e recebeu adubação de manutenção de 130 kg de nitrogênio/ha, parcelada em quatro aplicações. A área foi vedada ao acesso dos animais por aproximadamente 30 dias antes do processo de fenação.

Utilizaram-se quatro tourinhos Santa Gertrudes de $380 \mathrm{~kg}$ de peso corporal e 17 meses de idade, canulados no rúmen, segundo técnica descrita por Leão \& Coelho da Silva (1980). Os animais receberam os tratamentos necessários no pré e pós-operatórios para garantia de plena recuperação e, após recuperação completa, foram alojados individualmente em baias de alvenaria de $16 \mathrm{~m}^{2}$, com cocho, bebedouro e saleiro exclusivos.

Foram avaliadas quatro dietas experimentais (Tabelas 1 e 2), balanceadas para proporcionar dois potenciais de fermentação microbiana (y): alto (11 g de PB microbiana/MJ 
Tabela 1 - Composição bromatológica dos ingredientes utilizados

Table 1 - Chemical composition of the used ingredients

\begin{tabular}{|c|c|c|c|c|c|c|c|c|}
\hline $\begin{array}{l}\text { Ingrediente } \\
\text { Ingredient }\end{array}$ & $\begin{array}{l}\text { MS } \\
D M\end{array}$ & $\begin{array}{l}\text { MO } \\
\text { OM }\end{array}$ & $\begin{array}{r}\mathrm{PB} \\
C P\end{array}$ & EE & $\begin{array}{c}\text { Cinzas }^{1} \\
\text { Ash }\end{array}$ & $\begin{array}{l}\mathrm{CT} \\
\mathrm{TC}\end{array}$ & $\begin{array}{l}\text { FDN } \\
N D F\end{array}$ & $\begin{array}{l}\text { FDA } \\
A D F\end{array}$ \\
\hline Ingredient & $(\%)$ & & 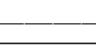 & - & MS $(\% D M)$ & & & - \\
\hline Milho moído (Corn ground) & 87,27 & 99,40 & 9,80 & 3,92 & 0,60 & 84,38 & 10,80 & 4,23 \\
\hline Farelo de algodão (Cottonseed meal) & 89,96 & 93,79 & 45,81 & 1,36 & 6,21 & 46,62 & 28,42 & 20,66 \\
\hline Farelo de soja (Soybean meal) & 90,22 & 93,67 & 51,40 & 1,93 & 6,33 & 40,35 & 14,90 & 11,86 \\
\hline
\end{tabular}

Tabela 2 - Composição percentual dos ingredientes e características das dietas

Table 2 - Percentage composition of ingredients and diet characteristics

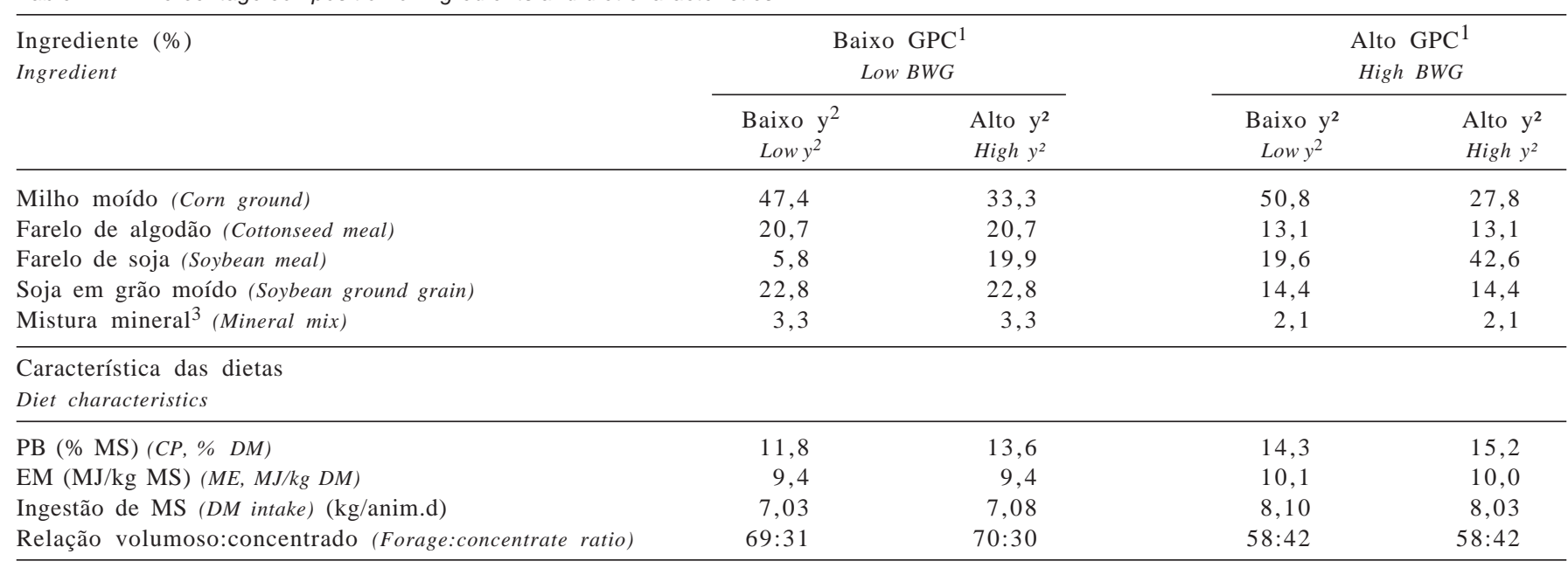

${ }_{1}^{1} \mathrm{GPC}$ - ganho diário estimado de peso corporal: alto $(1 \mathrm{~kg} / \mathrm{animal})$ e baixo $(0,5 \mathrm{~kg} / \mathrm{animal})$.

${ }^{2} \mathrm{y}$ - potencial estimado de fermentação microbiana: alto (11 g PB microbiana/MJ EM fermentável) e baixo (9,5 g PB microbiana/MJ EM fermentável).

1 BWG-estimated daily body weight gain: high $(1 \mathrm{~kg} /$ animal) and low $(0.5 \mathrm{~kg} /$ animal).

2 Estimated potential of microbial fermentation: high (11 g microbial CP/MJ fermentable ME and low (9.5 g microbial CP/MJ fermentable ME).

${ }^{3}$ Níveis de garantia por kg (Levels of guaranty, per $\mathrm{kg}$ ): Ca $-271 \mathrm{~g}, \mathrm{P}-29 \mathrm{~g}, \mathrm{Mg}-20 \mathrm{~g}, \mathrm{~S}-31 \mathrm{~g}, \mathrm{Na}-62 \mathrm{~g}, \mathrm{Zn}-1.350 \mathrm{mg}, \mathrm{Cu}-340 \mathrm{mg}, \mathrm{Fe}-1.064 \mathrm{mg}, \mathrm{Mn}-$ $940 \mathrm{mg}$, Co - $10 \mathrm{mg}, \mathrm{l}-25 \mathrm{mg}$ e Se - $10 \mathrm{mg}$.

de EM fermentável) e baixo (9,5 g de PB microbiana/MJ de EM fermentável); e dois ganhos diários de peso corporal (GPC): 0,5 e 1,0 kg/animal (AFRC, 1993).

Este trabalho fez parte de um conjunto de experimentos (Brito et al., 2006) nos quais as condições propostas visavam simular a suplementação com concentrado de bovinos mantidos em pastagem de capim-marandu durante a estação seca.

O período experimental teve duração de 64 dias, subdivididos em quatro períodos de 16 dias, os sete primeiros de adaptação à dieta. As bases do protocolo experimental seguiram as indicações de Fu et al. (2001) e Ítavo et al. (2002abcde). Durante todo o período experimental, os animais foram alimentados com feno ad libitum, parcelado em duas refeições ao dia (7 e 17h), e concentrado, fornecido apenas na primeira refeição do dia, de acordo com cada tratamento. Todos os dias pela manhã, as sobras de alimento nos cochos foram quantificadas e amostradas para controle da quantidade de alimento consumida pelos animais. Os animais foram pesados no início de cada subperíodo e no final do confinamento.

Em dois dias do período de coleta, foram retiradas alíquotas de $25 \mathrm{~mL}$ do líquido ruminal em recipiente com solução acidificante (1 mL de ácido sulfúrico a 50\%) para avaliação da concentração de $\mathrm{NH}_{3}$ e ácidos acético, propiônico e butírico. A avaliação foi efetuada 0, 3, 6, 9 e 12 horas após a refeição da manhã, realizando-se também a medida de $\mathrm{pH}$ do líquido ruminal em amostra fresca coletada nos mesmos horários, utilizando-se peagâmetro portátil de precisão $\pm 0,2$. A concentração de $\mathrm{NH}_{3}$ foi obtida de acordo com Fenner (1965); e os ácidos graxos foram determinados em cromatógrafo a gás e coluna com 1,6 m de comprimento após a centrifugação da amostra sob refrigeração a 13.000 rpm, durante 20 minutos, segundo recomendações de Erwin et al. (1961).

Para determinação da degradabilidade dos nutrientes, utilizou-se a técnica in situ (Mehrez \& Ørskov, 1977), nos 
tempos de 0,3 , 12 e 48 horas para os concentrados e de 0 , 6, 24 e 96 horas para o feno, segundo procedimentos experimentais descritos por Nocek (1988) e Sampaio (1998). Foram confeccionados sacos na medida de $5 \times 15 \mathrm{~cm}$, nos quais foram colocadas aproximadamente $7 \mathrm{~g}$ do alimento volumoso ou, no caso dos concentrados, $15 \mathrm{~g}$ de milho em grão moído ou farelo de algodão e 15, 20, e 25 g para os tempos de 3, 12 e 48 horas, respectivamente, para o farelo de soja e a soja em grão. Os sacos foram colocados em conjunto no rúmen e retirados após o tempo estipulado para cada amostra. Depois de removidos do rúmen, os sacos foram lavados em máquina, sob agitação e água corrente, até que a água ficasse límpida. Em seguida, foram secos em estufa com ventilação forçada a $65^{\circ} \mathrm{C}$ por 72 horas. Os sacos relativos ao tempo zero não foram incubados no rúmen; foram lavados em banho-maria a $39^{\circ} \mathrm{C}$ durante 15 minutos e depois em máquina, junto aos demais.

No resíduo obtido em cada saco, foram determinados os teores de MS, PB, carboidratos totais (CT) e cinzas para os concentrados, segundo AOAC (1995), e também o teor de FDN conforme Van Soest et al. (1991), no caso do feno. Depois das análises bromatológicas, as diferenças entre as quantidades de MS, MO, PB, CT e FDN do material incubado e do resíduo de cada nutriente recuperado em cada saco foram ajustadas em curvas de regressão não-lineares ao modelo matemático:

$$
\mathrm{p}_{\mathrm{n}}=\mathrm{a}+\mathrm{b}\left[1-\mathrm{e}^{-\mathrm{ct}}\right]
$$

no qual "p" representou a degradabilidade potencial da fração do alimento " $\mathrm{n}$ " no tempo " $\mathrm{t}$ ", de acordo com sua fração solúvel “a”, fração potencialmente degradável “b” e taxa de degradação “c”.

Em seguida, foi estimada a degradabilidade efetiva dos nutrientes de cada alimento (Ørskov \& McDonald, 1979), de acordo com a equação:

$$
\mathrm{P}_{\mathrm{n}}=\mathrm{a}+[\mathrm{b} \mathrm{x}(\mathrm{c} / \mathrm{c}+\mathrm{k})]
$$

em que "P" representa a degradação efetiva da fração do alimento "n" a uma taxa de passagem " $k$ " (foi estipulada taxa de passagem de $5 \% /$ hora).

As médias foram estudadas em esquema de quadrado latino $4 \times 4$ (animais $\times$ períodos), com quatro tratamentos no modelo fatorial $2 \times 2($ GPC $\times$ y). O modelo também incluiu o fator horário de coleta como causa adicional de variação no caso da avaliação de parâmetros com medidas repetidas no tempo. Foi realizada análise de variância por meio do teste F a 5\% de probabilidade (Sampaio, 1998).

\section{Resultados e Discussão}

Não foram encontradas interações significativas $(\mathrm{P}>0,05)$ entre os potenciais de ganho de peso e de fermen- tação microbiana para todas as variáveis de fermentação ruminal estudadas (Tabela 3). Com exceção da diferença $(\mathrm{P}<0,05)$ da concentração molar $(\mathrm{mM})$ de ácido propiônico nos diferentes potenciais de GPC e da diferença $(P<0,05)$ na concentração da $\mathrm{NH}_{3}$ entre os diferentes potenciais de fermentação ruminal, não foram observadas outras diferenças significativas $(\mathrm{P}>0,05)$ entre tratamentos nos demais parâmetros avaliados. Para elevar o potencial de fermentação, foi necessário prover maior quantidade de proteína degradável no rúmen (PDR), que, em última instância, foi convertida em $\mathrm{NH}_{3}$. No caso do ácido propiônico, o padrão de fermentação propiciado pelo maior nível de concentrado favoreceu a produção deste AGV.

Embora significativa, a diferença entre tratamentos para o ácido propiônico não permitiu que a relação acético:propiônico fosse alterada significativamente, uma vez que não foram encontradas diferenças $(P>0,05)$ na proporção molar. Essa diferença também não foi suficiente para alterar a relação ácetico:propiônico $(\mathrm{P}>0,05)$. Barbosa et al. (2001) alimentaram novilhos mestiços com feno de capim-elefante suplementado ou não com 2,8 kg de milho ou farelo de soja e obtiveram relação acetato:propionato de 3,24 e 3,95 (com e sem fornecimento de milho) e 3,34 e 3,85 (com e sem fornecimento de farelo de soja, respectivamente). Com o farelo de soja, os autores obtiveram concentrações semelhantes de ácidos acético e butírico (57,65 e 7,66 mM), mas o ácido propiônico diferiu entre os animais (20,1 e 13,6 Mm). A elevação do nível de concentrado na dieta, segundo esses autores, interferiu na concentração ruminal de ácido propiônico, como ocorreu neste trabalho.

$\mathrm{O}$ pH ruminal não diferiu $(\mathrm{P}>0,05)$ entre tratamentos para diferentes potenciais de fermentação e GPC (Tabela 4). Após a refeição, houve redução do $\mathrm{pH}$, que atingiu o menor valor $(6,23), 7$ horas e 48 minutos após a refeição, quando começou a elevar-se novamente. Paulino et al. (2002) mantiveram novilhos em pastagem de Brachiaria decumbens e suplementaram (4 kg/animal) com concentrado composto de diferentes fontes protéicas. Esses autores determinaram que nenhum tratamento reduziu o $\mathrm{pH}$ ruminal abaixo de $6 \mathrm{e}$ concluíram que a suplementação não alterou o pH para níveis indesejáveis, fato também observado neste ensaio.

Para a $\mathrm{NH}_{3}$ ruminal, foram observadas diferenças $(\mathrm{P}<0,05)$ entre os tratamentos para potencial de fermentação. A concentração de $\mathrm{NH}_{3}$ foi maior ao longo do período pós-prandial para a dieta formulada visando maior potencial de fermentação microbiana, em virtude de seu maior aporte de PDR. Nos animais alimentados com essa dieta, a concentração máxima de $\mathrm{NH}_{3}$ foi de 28,53 mg/100 mL, 6 horas após a refeição da manhã, enquanto naqueles alimentados com a dieta para menor potencial de fermentação 
Tabela 3 - Parâmetros de fermentação ruminal de tourinhos Santa Gertrudes alimentados com feno de capim-marandu e concentrado ajustados para diferentes potenciais de fermentação e produção

Table 3 - Parameters of ruminal fermentation by Santa Gertrudis young bulls fed palisedagrass hay and concentrate for different fermentation and production potentials

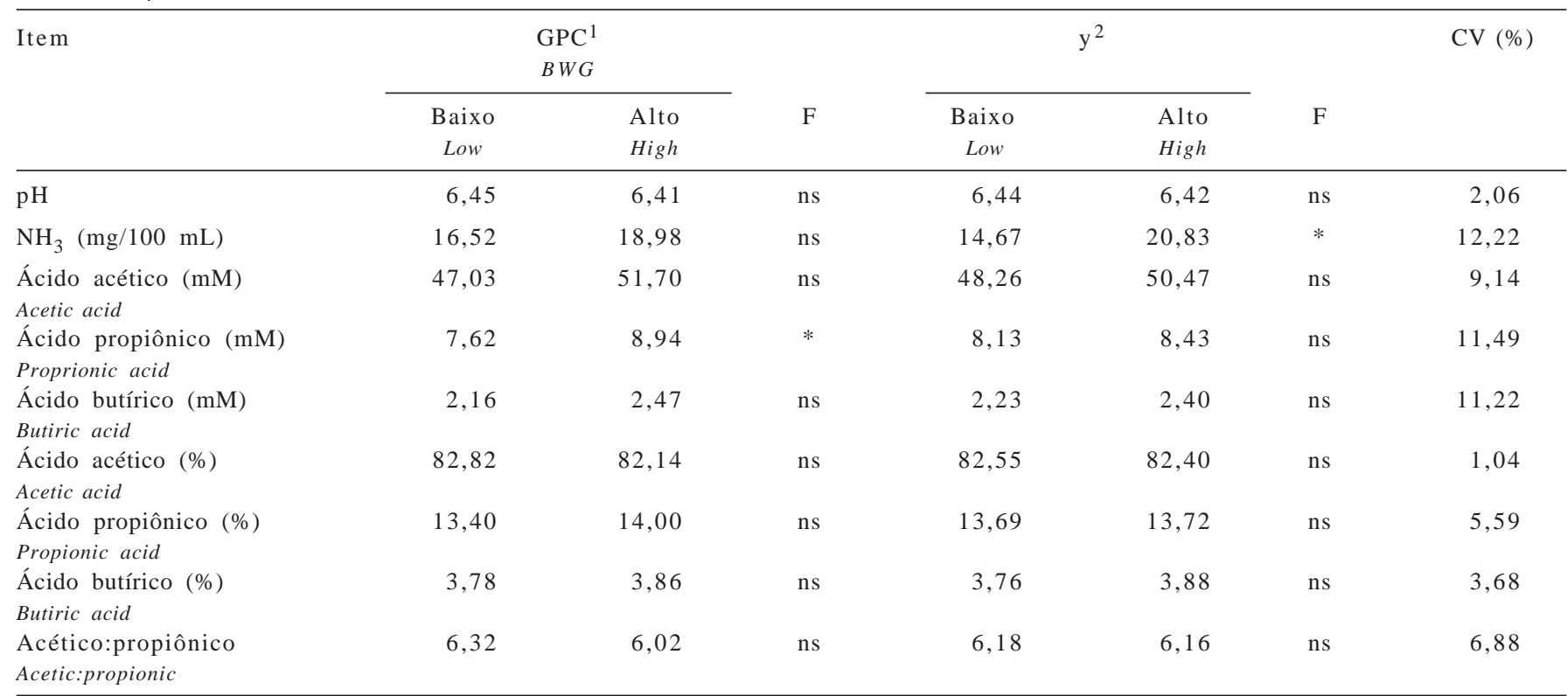

ns - não-significativo; * $(P<0,05)$, teste $F$ (ns - not significant; * $P<0.05, F$ test).

${ }^{1}$ GPC - ganho diário estimado de peso corporal: alto (1 kg/animal) e baixo (0,5 kg/animal) (BWG-estimated daily body weight gain: high [1 kg/animal] and low [0.5 kg/animal]). $2 \mathrm{y}$ - potencial estimado de fermentação microbiana: alto (11 g PB microbiana/MJ EM fermentável) e baixo (9,5 g PB microbiana/MJ EM fermentável) (Estimated potential of microbial fermentation: high [11 g microbial CP/MJ fermentable ME] and low [9.5 g microbial CP/MJ fermentable ME]).

Tabela 4 - Equações de regressão dos parâmetros de fermentação ruminal em tourinhos Santa Gertrudes após refeição da manhã $(X=$ horas) com dieta composta de feno de capim-marandu e concentrado

Table 4 - Equations of regression of ruminal fermentation parameters by Santa Gertrudis young bulls, after morning feeding ( $X=$ hours) with diets composed by palisedagrass hay and concentrate

\begin{tabular}{|c|c|c|c|}
\hline Item & $\begin{array}{l}\text { Regressão } \\
\text { Regression }\end{array}$ & $\mathrm{R}^{2}$ & $\mathrm{~F}$ \\
\hline $\mathrm{pH}$ & $\hat{Y}=0,0077 X^{2}-0,1224 X+6,7858$ & 0,984 & $* *$ \\
\hline y alto $(\text { high } y)^{1}$ & $\hat{Y}=-0,4284 X^{2}+5,1217 X+13,218$ & 0,7322 & $* *$ \\
\hline
\end{tabular}

Concentração molar do ácido (mM)

Acid molar concentration

Ácético (Acetic)

Propiônico no tratamento

Proprionic of treatment

GPC alto (High BWG)

GPC baixo (Low $B W G$ )

Butírico (Butiric)

Relação acético:propiônico (Acetic:propionic ratio)

Proporção molar do ácido (\%) (Molar proportion of acid, \%)

Acético (Acetic)

Propiônico (Propionic)

Butírico (Butiric)
$\hat{\mathrm{Y}}=-0,2524 \mathrm{X}^{2}+3,4304 \mathrm{X}+41,983$

0,9327

$\hat{\mathrm{Y}}=-0,0869 \mathrm{X}^{2}+1,3079 \mathrm{X}+5,7849$

$\hat{Y}=-0,0592 X^{2}+0,8144 X+5,9324$

$\hat{\mathrm{Y}}=-0,0241 \mathrm{X}^{2}+0,3419 \mathrm{X}+1,5528$

0,9751

0,9759

0,9259

$\hat{\mathrm{Y}}=0,0253 \mathrm{X}^{2}-0,4113 \mathrm{X}+7,348$

0,9428

$\hat{\mathrm{Y}}=0,0637 \mathrm{X}^{2}-0,9886 \mathrm{X}+85,129$

0,9773

$\hat{Y}=-0,0428 X^{2}+0,6805 X+11,749$

0,9824

$\hat{\mathrm{Y}}=-0,0209 \mathrm{X}^{2}+0,3081 \mathrm{X}+3,1226$
$*$

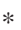

*

$*$

$*$

ns - não-significativo; * $(P<0,05),{ }^{* *}(P<0,01)$ teste $F\left(n s-\right.$ not significant; ${ }^{*} P<0.05, P<0.01, F$ test).

1 GPC - ganho diário estimado de peso corporal: alto (1 kg/animal) e baixo (0,5 kg/animal) (BWG - estimated daily body weight gain: high [1 kg/animal] and low [0.5 kg/animal]).

$2 \mathrm{y}$ - potencial estimado de fermentação microbiana: alto (11 g PB microbiana/MJ EM fermentável) e baixo (9,5 g PB microbiana/MJ EM fermentável) (Estimated potential of microbial fermentation: high [11 g microbial CP/MJ fermentable ME] and low [9.5 g microbial CP/MJ fermentable ME]). 
microbiana essa concentração foi de $19 \mathrm{mg} / 100 \mathrm{~mL}$ no mesmo tempo. Mesmo com a diferença de valores, o comportamento das curvas foi semelhante em ambos os casos.

As dietas para diferentes GPC proporcionaram níveis semelhantes de $\mathrm{NH}_{3}$ ruminal, mesmo com as diferentes proporções de concentrado. Neste estudo, a concentração de $\mathrm{NH}_{3}$ manteve-se acima dos valores observados por Paulino et al. (2002), em novilhos mantidos em pastagem de Brachiaria decumbens e suplementados com $4 \mathrm{~kg}$ de concentrado/animal. Dias et al. (2000) obtiveram nível de $\mathrm{NH}_{3}$ ruminal máximo de 18 e $20 \mathrm{mg} / 100 \mathrm{~mL}$, 2 horas e 55 minutos após alimentação, para 30 e 42,5\% de concentrado na MS da dieta, respectivamente, em novilhos Limousin-Nelore alimentadas com feno de coastcross e suplemento.

De acordo com Satter \& Slyter (1974), a concentração de $\mathrm{NH}_{3}$ no líquido ruminal para eficiente crescimento microbiano deve se manter entre 5 e $8 \mathrm{mg} / 100 \mathrm{~mL}$. Neste trabalho, as médias de $\mathrm{NH}_{3}$ ruminal estiveram acima do limite superior recomendado por esses autores. No entanto, de acordo com recomendações de Preston, citado por Queiroz et al. (1998), a concentração mínima de $20 \mathrm{mg} / 100 \mathrm{~mL}$ é sugerida para alimentos com maior conteúdo de parede celular, o que foi verificado nos animais alimentados com dietas para alto GPC e alto potencial de fermentação.

As concentrações dos ácidos acético e butírico não diferiram entre os animais alimentados com as dietas para diferentes potenciais de fermentação e/ou GPC (Tabela 3). As maiores concentrações, de 53,64 e 2,76 mM, ocorreram 6 horas e 48 minutos e 7 horas e 6 minutos após a refeição da manhã, respectivamente.

A concentração molar de ácido propiônico no líquido ruminal diferiu entre as dietas para diferentes GPC. A concentração foi maior ao longo do período pós-prandial para a dieta formulada visando maior ganho de peso.

A relação entre a concentração molar dos ácidos acético e propiônico no líquido ruminal não foi significativa para todas as dietas avaliadas. No entanto, a curva de variação ao longo do tempo obtida para as dietas foi representativa $(\mathrm{P}<0,05)$ e indicou que a menor relação aferida foi de 5,68 , 8 horas pós-alimentação.

Não houve qualquer diferença entre as dietas formuladas para diferentes potenciais de fermentação ou ganho de peso corporal quanto à proporção molar dos ácidos graxos

Tabela 5 - Degradação ruminal de MS, MO, PB, FDN e CT do feno de capim-marandu

Table 5 - Ruminal degradation of DM, OM, CP, NDF and TC of palisadegrass hay

\begin{tabular}{|c|c|c|c|c|c|c|}
\hline \multirow[t]{2}{*}{$\begin{array}{l}\text { Fração } \\
\text { Fraction }\end{array}$} & \multirow[t]{2}{*}{$\begin{array}{c}\text { Parâmetro } \\
\text { Parameter }\end{array}$} & \multicolumn{2}{|c|}{$\begin{array}{c}\mathrm{GPC}^{1} \\
B W G\end{array}$} & \multicolumn{2}{|c|}{$y^{2}$} & \multirow[t]{2}{*}{ CV (\%) } \\
\hline & & $\begin{array}{c}\text { Baixo } \\
\text { Low }\end{array}$ & $\begin{array}{l}\text { Alto } \\
\text { High }\end{array}$ & $\begin{array}{c}\text { Baixo } \\
\text { Low }\end{array}$ & $\begin{array}{l}\text { Alto } \\
\text { High }\end{array}$ & \\
\hline $\begin{array}{l}\text { MS } \\
D M\end{array}$ & $\begin{array}{l}\mathrm{b}^{3} \\
\mathrm{c} \\
\text { DE5 } \\
\text { ED5 }\end{array}$ & $\begin{array}{r}56,1 \\
0,036 \\
29,7\end{array}$ & $\begin{array}{r}54,9 \\
0,036 \\
28,9\end{array}$ & $\begin{array}{r}55,1 \\
0,035 \\
28,9\end{array}$ & $\begin{array}{r}55,8 \\
0,037 \\
29,7\end{array}$ & $\begin{array}{r}3,61 \\
12,91 \\
6,78\end{array}$ \\
\hline $\begin{array}{l}\text { MO } \\
\text { OM }\end{array}$ & $\begin{array}{l}\mathrm{b} \\
\mathrm{c} \\
\text { DE5 } \\
\text { ED5 }\end{array}$ & $\begin{array}{r}57,7 \\
0,036 \\
27,8\end{array}$ & $\begin{array}{r}56,0 \\
0,035 \\
27,1\end{array}$ & $\begin{array}{r}56,3 \\
0,035 \\
27,1\end{array}$ & $\begin{array}{r}57,4 \\
0,036 \\
27,8\end{array}$ & $\begin{array}{r}3,43 \\
13,20 \\
7,47\end{array}$ \\
\hline $\begin{array}{l}\mathrm{PB} \\
C P\end{array}$ & $\begin{array}{l}\mathrm{b} \\
\mathrm{c} \\
\mathrm{DE} 5 \\
\text { ED5 }\end{array}$ & $\begin{array}{r}35,9 \\
0,021 \\
32,6\end{array}$ & $\begin{array}{r}35,2 \\
0,021 \\
31,5\end{array}$ & $\begin{array}{r}35,3 \\
0,022 \\
31,8\end{array}$ & $\begin{array}{r}35,8 \\
0,020 \\
32,3\end{array}$ & $\begin{array}{r}6,39 \\
50,94 \\
11,12\end{array}$ \\
\hline $\begin{array}{l}\mathrm{CT} \\
T C\end{array}$ & $\begin{array}{l}\mathrm{b} \\
\mathrm{c} \\
\mathrm{DE} 5 \\
\text { ED5 }\end{array}$ & $\begin{array}{r}59,7 \\
0,036 \\
27,8\end{array}$ & $\begin{array}{r}57,6 \\
0,039 \\
27,8\end{array}$ & $\begin{array}{r}58,3 \\
0,038 \\
27,8\end{array}$ & $\begin{array}{r}59,0 \\
0,037 \\
27,7\end{array}$ & $\begin{array}{r}3,98 \\
12,20 \\
6,81\end{array}$ \\
\hline
\end{tabular}


Tabela 6 - Degradação ruminal de MS, MO, PB e CT do milho moído

Table 6 - Ruminal degradation of DM, OM, CP and TC of ground corn

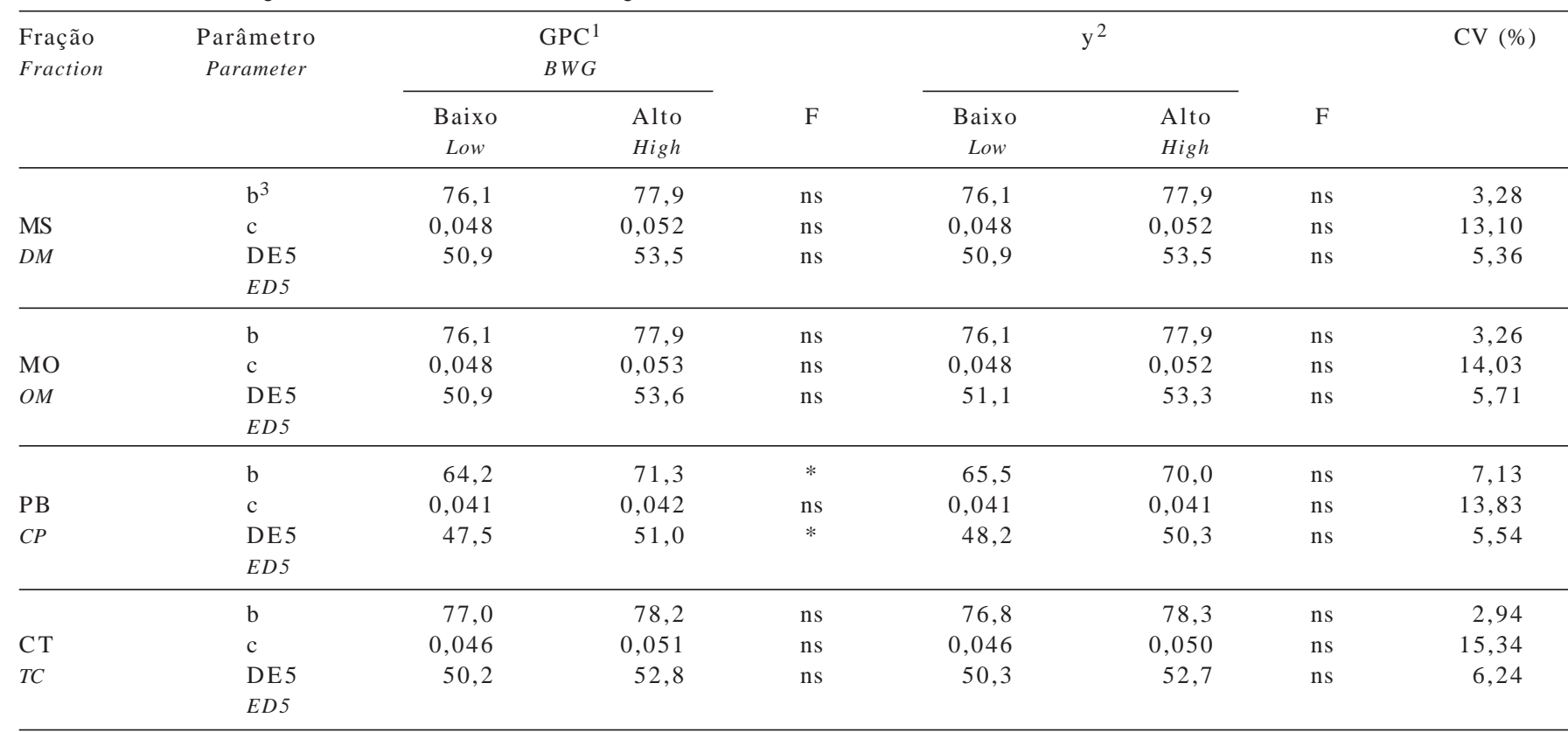

ns - não-significativo; * $(\mathrm{P}<0,05)$, teste $\mathrm{F}$ (ns - not significant; * $P<0.05, F$ test $)$

${ }^{1} \mathrm{GPC}$ - ganho diário estimado de peso corporal: alto (1 kg/animal) e baixo $(0,5 \mathrm{~kg} / \mathrm{animal})$.

2 y - potencial estimado de fermentação microbiana: alto (11 g PB microbiana/MJ EM fermentável) e baixo (9,5 g PB microbiana /MJ EM fermentável).

3 b - fração potencialmente degradável (\%), c - taxa de degradação (\%/h) e DE5 - degradabilidade efetiva (\%) a 5\%/hora.

1 BWG - estimated daily body weight gain: high (1 kg/animal) and low $(0.5 \mathrm{~kg} / \mathrm{animal})$.

2 Estimated potential of microbial fermentation: high (11 g microbial CP/MJ fermentable ME and low (9.5 g microbial CP/MJ fermentable ME).

$3 \mathrm{~b}$ - fraction potentially degradable (\%), c - degradation rate (\%/h) and ED 5 - effective degradability (\%) at $5 \% / h$.

voláteis. Todavia, a curva de variação ao longo do tempo obtida nos animais alimentados com cada uma das dietas, dos três AGV avaliados, foi representativa $(\mathrm{P}<0,05)$. A menor proporção de ácido acético foi de $81,3 \%$, às 7 horas e 48 minutos após a refeição. Diferente do comportamento observado para a concentração molar, a proporção molar do ácido propiônico não apresentou variação significativa quando consideradas as diferentes dietas testadas; a proporção máxima obtida foi de 14,5\%, 8 horas após a refeição. De forma análoga à avaliação de concentração molar, a proporção molar do ácido butírico também foi similar entre as dietas testadas e a proporção molar máxima (4,19\%) foi obtida 9 horas e 6 minutos após a refeição.

A quantificação da fração “a” (solúvel) para MS, MO, PB e CT do feno de capim-marandu foi de 6,1; 3,9; 22,4 e $2,8 \%$, respectivamente. Por ser um alimento volumoso, a reduzida média da fração “a” da FDN (Tabela 5) está coerente com resultados descritos por Veloso et al. (2000), que obtiveram valor nulo para diversas forrageiras tropicais. $\mathrm{O}$ mesmo foi verificado por Ítavo et al. (2002a).

Não foram observadas diferenças $(\mathrm{P}>0,05)$ entre as médias das variáveis avaliadas para o feno de capim-marandu nas diferentes dietas avaliadas. Apesar do interesse principal da degradabilidade efetiva a $5 \% /$ hora de taxa de passagem (DE5) das frações PB e FDN de forrageiras, não foi obser- vada diferença $(\mathrm{P}>0,05)$ entre os níveis de produção e/ou potenciais de fermentação.

A quantificação da fração "a” (solúvel) para MS, MO, PB e CT do milho em grão moído (Tabela 6) foi de 13,8; 13,8; 18,8 e $13,5 \%$, respectivamente.

Bürguer et al. (2000) observaram médias da fração "a” para MS e PB do milho de 13,69 e 17,66\%, respectivamente, similares às obtidas neste estudo. Esses autores também relataram taxa "c" de 5,47 e 4,95\%/hora para MS e PB do milho. Valadares Filho(1995) pesquisou em diversos trabalhos e relatou valores médios de degradação da PB do milho de 21,2\%; 78,0\%; 0,019\%/hora e 42,8\% para “a”, "b” e “c" e degradabilidade efetiva a 5\%/h. O AFRC (1993) adotou os valores de 26,0\%; 69,0\%; 0,01\%/hora e 32,3\% para “a”, “b”, "c" e DE5 da PB do milho.

À exceção da fração "b” e DE5 para a PB $(\mathrm{P}<0,05)$ do milho em grão, não foi observada diferença entre as demais variáveis estudadas $(\mathrm{P}>0,05)$. Na prática, como a proteína do milho representou $15 \%$ da PB total da dieta, a diferença na DE5 representaria alguma importância técnica, uma vez que sob maiores taxas de GPC houve maior degradação desta fração nutritiva do milho. A taxa "c" obtida neste trabalho foi sensivelmente maior que a adotada pelo AFRC (1993) e foi a principal causa da variação observada para a DE5 da PB do milho. 
Tabela 7 - Degradação ruminal de MS, MO, PB e CT do grão de soja moído

Table 7 - Ruminal degradation of DM, OM, CP and TC of ground soybean seed

\begin{tabular}{|c|c|c|c|c|c|c|}
\hline \multirow[t]{2}{*}{$\begin{array}{l}\text { Fração } \\
\text { Fraction }\end{array}$} & \multirow[t]{2}{*}{$\begin{array}{l}\text { Parâmetro } \\
\text { Parameter }\end{array}$} & \multicolumn{2}{|c|}{$\begin{array}{l}\mathrm{GPC}^{1} \\
B W G\end{array}$} & \multicolumn{2}{|c|}{$y^{2}$} & \multirow[t]{2}{*}{ CV (\%) } \\
\hline & & $\begin{array}{l}\text { Baixo } \\
\text { Low }\end{array}$ & $\begin{array}{l}\text { Alto } \\
\text { High }\end{array}$ & $\begin{array}{c}\text { Baixo } \\
\text { Low }\end{array}$ & $\begin{array}{l}\text { Alto } \\
\text { High }\end{array}$ & \\
\hline & $b^{3}$ & 62,7 & 62,8 & 62,6 & 62,8 & 0,46 \\
\hline MS & c & 0,055 & 0,052 & 0,053 & 0,054 & 20,32 \\
\hline$D M$ & $\begin{array}{l}\text { DE } 5 \\
\text { ED5 }\end{array}$ & 68,7 & 67,5 & 67,8 & 68,5 & 4,62 \\
\hline $\begin{array}{l}\text { MO } \\
O M\end{array}$ & $\begin{array}{l}\mathrm{b} \\
\mathrm{c} \\
\mathrm{DE} 5 \\
\text { ED5 }\end{array}$ & $\begin{array}{r}62,6 \\
0,052 \\
67,9\end{array}$ & $\begin{array}{r}62,7 \\
0,049 \\
66,6\end{array}$ & $\begin{array}{r}62,6 \\
0,050 \\
66,9\end{array}$ & $\begin{array}{r}62,8 \\
0,051 \\
67,6\end{array}$ & $\begin{array}{r}0,47 \\
21,77 \\
5,01\end{array}$ \\
\hline $\begin{array}{l}\mathrm{PB} \\
C P\end{array}$ & $\begin{array}{l}\mathrm{b} \\
\mathrm{c} \\
\text { DE5 } \\
\text { ED5 }\end{array}$ & $\begin{array}{r}73,3 \\
0,067 \\
67,8\end{array}$ & $\begin{array}{r}73,5 \\
0,062 \\
66,3\end{array}$ & $\begin{array}{r}73,4 \\
0,064 \\
67,0\end{array}$ & $\begin{array}{r}73,5 \\
0,064 \\
67,1\end{array}$ & $\begin{array}{r}0,31 \\
18,12 \\
4,93\end{array}$ \\
\hline $\begin{array}{l}\mathrm{CT} \\
\mathrm{TC}\end{array}$ & $\begin{array}{l}\mathrm{b} \\
\mathrm{c} \\
\mathrm{DE} 5 \\
\text { ED5 }\end{array}$ & $\begin{array}{r}63,3 \\
0,066 \\
70,0\end{array}$ & $\begin{array}{r}63,5 \\
0,064 \\
69,4\end{array}$ & $\begin{array}{r}63,2 \\
0,064 \\
69,3\end{array}$ & $\begin{array}{r}63,6 \\
0,066 \\
70,1\end{array}$ & $\begin{array}{r}1,07 \\
13,75 \\
3,36\end{array}$ \\
\hline
\end{tabular}

${ }^{1} \mathrm{GPC}$ - ganho diário estimado de peso corporal: alto $(1 \mathrm{~kg} / \mathrm{animal})$ e baixo $(0,5 \mathrm{~kg} / \mathrm{animal})$.

${ }^{2}$ y - potencial estimado de fermentação microbiana: alto (11 g PB microbiana/MJ EM fermentável) e baixo (9,5 g PB microbiana/MJ EM fermentável).

$3 \mathrm{~b}$ - fração potencialmente degradável (\%), c - taxa de degradação (\%/h) e DE5 - degradabilidade efetiva (\%) a 5\%/hora.

1 BWG - estimated daily body weight gain: high (1 kg/animal) and low $(0,5 \mathrm{~kg} / \mathrm{animal})$.

2 Estimated potential of microbial fermentation: high (11 g microbial CP/MJ fermentable ME and low (9.5 g microbial CP/MJ fermentable ME).

${ }^{3} \mathrm{~b}$ - fraction potentially degradable (\%), c - degradation rate (\%/h) and ED 5 - effective degradability (\%) at $5 \% / \mathrm{h}$.

A quantificação da fração "a” (solúvel) para MS, MO, PB e CT da soja em grão foi de 36,2; 36,2; 26,2 e 34,3\%, respectivamente (Tabela 7). Não houve diferença significativa $(\mathrm{P}>0,05)$ entre as dietas para a soja em grão. Apesar da ausência de diferenças, a degradação efetiva da PB manteve-se abaixo dos valores encontrados na literatura. Em revisão, Valadares Filho (1995) citou médias de degradação da PB da soja integral de 34,6\%; 65,0\%; 0,077\%/hora e 78,0\% para as frações "a”, "b” e “c” e DE5, respectivamente. A DE5 da PB da soja integral encontrada neste trabalho foi menor que a relatada por esse autor, possivelmente em virtude da menor taxa " $c$ " observada nesta pesquisa.

As variáveis obtidas para o farelo de soja, que não apresentaram comportamento de interação dos tratamentos, são apresentadas na Tabela 8. Todas as variáveis determinadas para o farelo de soja foram estatisticamente semelhantes $(P>0,05)$ entre as dietas. A quantificação da fração “a” para MS, MO, PB e CT do farelo de soja foi de 31,5; 31,5; 22,9 e 37,6\%, respectivamente.

As frações $\mathrm{MO}$ e CT não diferiram $(\mathrm{P}>0,05)$ quanto à degradabilidade ruminal. A ausência de diferenças na fração MO pode ser atribuída à pequena magnitude nas diferenças de PB (50\% da MS do alimento), associada às semelhanças na fração CT. Considerando que a fração CT compõe $40 \%$ da MS desse alimento, é preciso considerar a importância da disponibilidade energética para a microbiota ruminal, que representa uma das partes na abordagem bilateral (proteína $\times$ energia) do processo de síntese de proteína microbiana no rúmen.

As variáveis determinadas para o farelo de soja cuja interação foi significativa $(\mathrm{P}<0,05)$ são apresentadas na Tabela 9. No caso do farelo de soja, um suplemento protéico de elevada importância, ressalta-se a maior DE5 da PB para alto GPC sob alto potencial de fermentação $(\mathrm{P}<0,05)$. Esta condição não foi repetida quando os animais foram alimentados para menor GPC.

Bürguer et al. (2000) relataram taxa "c" de 7,34 e 8,16\%/hora para MS e PB do farelo de soja. Valadares Filho (1995) compilou dados de diversos autores e citou os valores médios dos parâmetros de degradação da PB do farelo de soja de 20,2\%; 77,0\%; 0,066\%/hora e 65,6\% para as frações "a", "b” e "c" e para a DE5, que, neste trabalho, apresentou decréscimo médio de mais de 10 pontos percentuais, o que é indesejável. Nos trabalhos compilados, não foi possível esclarecer sob quais circunstâncias quantitativas e qualitativas de forragem os valores foram obtidos.

A principal causa dessa menor DE5 em relação à média descrita na literatura foi a menor taxa de degradação. O 
Tabela 8 - Degradação ruminal de MS, MO, PB e CT do farelo de soja

Table 8 - Ruminal degradation of DM, OM, CP and TC of soybean meal

\begin{tabular}{|c|c|c|c|c|c|c|}
\hline \multirow[t]{2}{*}{$\begin{array}{l}\text { Fração } \\
\text { Fraction }\end{array}$} & \multirow[t]{2}{*}{$\begin{array}{c}\text { Parâmetro } \\
\text { Parameter }\end{array}$} & \multicolumn{2}{|c|}{$\begin{array}{c}\text { GPC }^{1} \\
B W G\end{array}$} & \multicolumn{2}{|c|}{$y^{2}$} & \multirow[t]{2}{*}{ CV (\%) } \\
\hline & & $\begin{array}{c}\text { Baixo } \\
\text { Low }\end{array}$ & $\begin{array}{l}\text { Alto } \\
\text { High }\end{array}$ & $\begin{array}{c}\text { Baixo } \\
\text { Low }\end{array}$ & $\begin{array}{l}\text { Alto } \\
\text { High }\end{array}$ & \\
\hline $\begin{array}{l}\text { MS } \\
D M\end{array}$ & $b^{3}$ & 64,9 & 64,1 & 63,7 & 65,3 & 3,29 \\
\hline $\begin{array}{l}\mathrm{PB} \\
C P\end{array}$ & $\mathrm{~b}$ & 73,5 & 72,3 & 71,7 & 74,0 & 3,75 \\
\hline $\begin{array}{l}\mathrm{CT} \\
\mathrm{TC}\end{array}$ & $\begin{array}{l}\mathrm{b} \\
\mathrm{c} \\
\mathrm{DE} 5 \\
\text { ED5 }\end{array}$ & $\begin{array}{r}58,6 \\
0,051 \\
66,7\end{array}$ & $\begin{array}{r}58,2 \\
0,055 \\
67,7\end{array}$ & $\begin{array}{r}57,9 \\
0,055 \\
67,8\end{array}$ & $\begin{array}{r}58,8 \\
0,051 \\
66,7\end{array}$ & $\begin{array}{r}2,75 \\
16,72 \\
3,20\end{array}$ \\
\hline
\end{tabular}

Tabela 9 - Degradação ruminal da MS e PB do farelo de soja Table 9 - Ruminal degradation of DM and CP of soybean meal

\begin{tabular}{|c|c|c|c|c|}
\hline \multirow{3}{*}{$\begin{array}{l}\mathrm{GPC}^{1} \\
B W G\end{array}$} & \multicolumn{2}{|c|}{$y^{2}$} & & \multirow[t]{3}{*}{ CV (\%) } \\
\hline & Baixo & Alto & Média & \\
\hline & Low & High & Mean & \\
\hline
\end{tabular}

MS $c^{3}\left(D M c^{3}\right)$

\begin{tabular}{lrrrr} 
Baixo (Low) & $0,046 \mathrm{Aa}$ & $0,040 \mathrm{Bb}$ & 0,043 & \\
Alto (High) & $0,041 \mathrm{Bb}$ & $0,050 \mathrm{Aa}$ & 0,046 & \\
Média (Mean) & 0,044 & 0,045 & - & 5,81 \\
\hline \multicolumn{5}{c}{ MS DE5 (DM ED5) } \\
Baixo (Low) & $62,5 \mathrm{Aa}$ & $60,0 \mathrm{Ba}$ & 61,23 & \\
Alto (High) & $59,5 \mathrm{Bb}$ & $63,8 \mathrm{Aa}$ & 61,66 & \\
Média (Mean) & 61,0 & 61,9 & - & 2,63
\end{tabular}

$\mathrm{PB}$ c $(C P$ c)

\begin{tabular}{lrrrr} 
Baixo (Low) & $0,037 \mathrm{Aa}$ & $0,033 \mathrm{Ba}$ & & \\
Alto (High) & $0,032 \mathrm{Ab}$ & $0,043 \mathrm{Aa}$ & & \\
Média (Mean) & 0,034 & 0,038 & - & 10,53 \\
\hline
\end{tabular}

PB DE5 (CP ED5)

\begin{tabular}{lrrrr} 
Baixo (Low) & $53,9 \mathrm{Aa}$ & $51,4 \mathrm{Aa}$ & 52,6 & \\
Alto (High) & $49,5 \mathrm{Ab}$ & $56,9 \mathrm{Aa}$ & 53,2 & \\
Média (Mean) & 51,7 & 54,1 & - & 6,02 \\
\hline
\end{tabular}

Médias seguidas de letras distintas, minúsculas (linha) e maiúscula (coluna), diferem $(P<0,05)$ pelo teste $F$.

${ }^{1} \mathrm{GPC}$ - ganho diário estimado de peso corporal: alto (1 kg/animal) e baixo $(0,5 \mathrm{~kg} / \mathrm{animal})$.

2 y-potencial estimado de fermentação microbiana: alto (11 g PB microbiana/ MJ EM fermentável) e baixo (9,5 g PB microbiana/MJ EM fermentável).

${ }^{3} \mathrm{c}$ - taxa de degradação (\%/hora) e DE5 - degradabilidade efetiva (\%) a 5\%/ hora.

Means followed by different letters, small (row) and capital (column), are different $(P<0.05)$ by F test.

${ }^{1}$ BWG - estimated daily body weight gain: high (1 kg/animal) and low (0.5 kg/animal).

2 Estimated potential of microbial fermentation: high (11 g microbial CP/M Jermentable ME and low ( $9.5 \mathrm{~g} \mathrm{microbial} \mathrm{CP/MJ} \mathrm{fermentable} \mathrm{ME}$ ).

${ }^{3} \mathrm{c}$ - degradation rate $(\% / h)$ and ED 5 - effective degradability (\%) at $5 \% / \mathrm{h}$.
AFRC (1993) adotou os valores de 8,0\%; 92,0\%; 0,08\%/hora e 62,9\% para “a”, “b”, “c” e DE5 da PB do farelo de soja, respectivamente.

A quantificação da fração “a” (solúvel) para MS, MO, PB e CT do farelo de algodão foi de 22,5; 22,5; 25,0 e 7,9\%, respectivamente. As demais variáveis medidas para esse alimento que não apresentaram comportamento de interação dos tratamentos ou tratamentos $\times$ tempo de incubação são descritas na Tabela 10.

Para todas as variáveis medidas no farelo de algodão, a degradação efetiva a 5\%, de grande relevância prática nutricional, não diferiu $(\mathrm{P}>0,05)$ entre as dietas. Mesmo que o farelo de algodão seja um alimento com maior teor de fibra, não houve diferença $(\mathrm{P}>0,05)$ na degradação dos $\mathrm{CT}$ entre as dietas, assim como observado para o perfil de degradação do feno de capim-marandu.

Houve diferenças entre as médias da fração "b” da MS e MO do farelo de algodão. Foi contabilizada maior média $(\mathrm{P}<0,05)$ das dietas para baixo GPC e alto potencial de fermentação. Nas dietas para alto GPC, observou-se maior $(\mathrm{P}<0,05)$ taxa de degradação das frações MS e MO, fato não verificado para as dietas com diferentes potenciais de fermentação $(\mathrm{P}>0,05)$.

A fração "b" da PB do farelo de algodão não apresentou interação das dietas (Tabela 11). Nas dietas para maior GPC, observou-se maior média $(\mathrm{P}<0,05)$ no maior potencial de fermentação. No entanto, sob condições de baixa fermentação, houve vantagem $(\mathrm{P}<0,05)$ numérica consistente para 
Tabela 10 - Degradação ruminal de MS, MO, PB e CT do farelo de algodão Table 10 - Ruminal degradation of DM, OM, CP and TC of the cottonseed meal

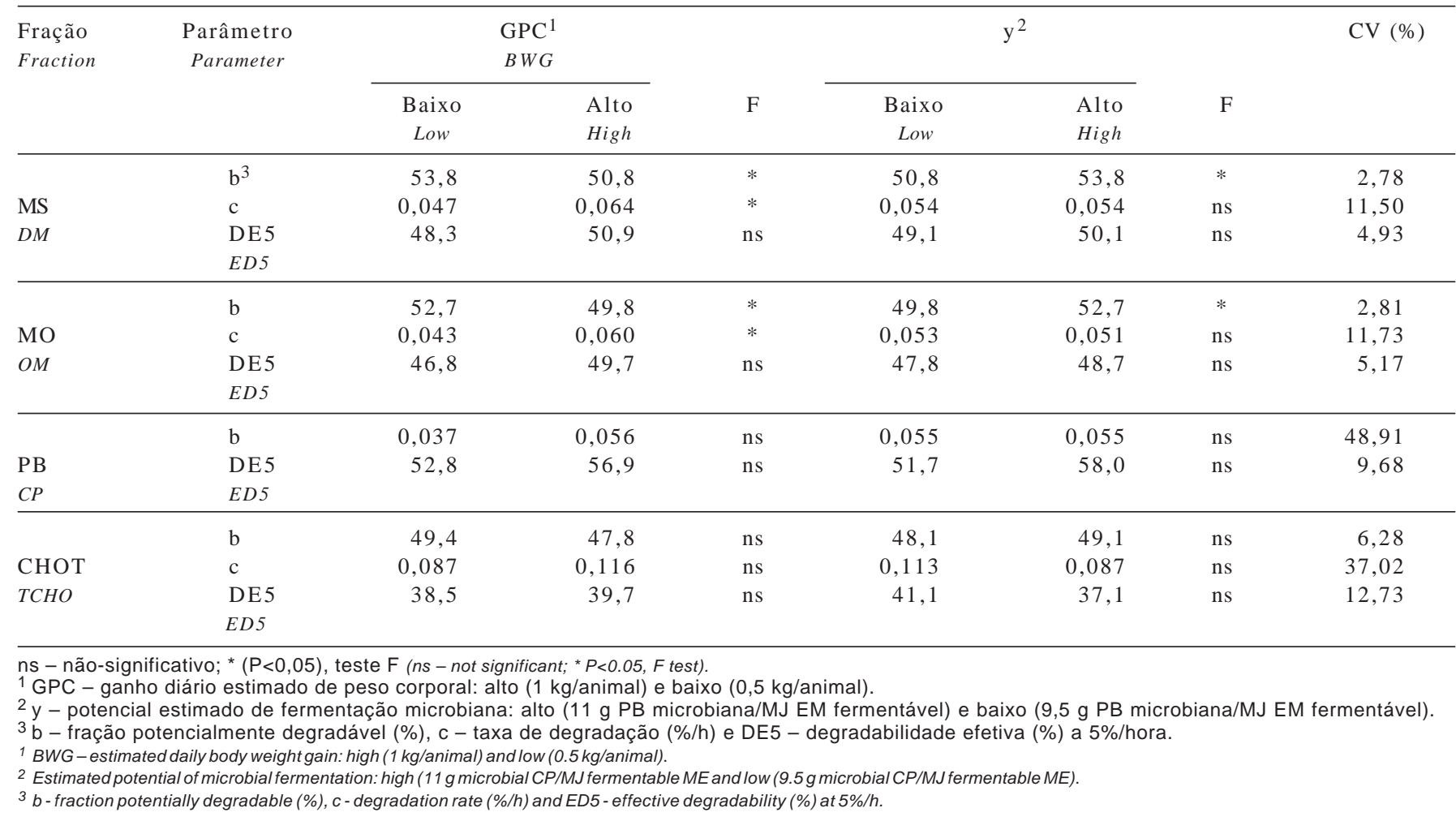

Tabela 11 - Parâmetro "b" (em \%) da degradação ruminal da PB do farelo de algodão

Table 11 - Parameter "b" (in \%) of ruminal degradation of CP of cottonseed meal

\begin{tabular}{|c|c|c|c|c|}
\hline \multirow{2}{*}{$\begin{array}{l}\mathrm{GPC}^{1} \\
B W G\end{array}$} & \multicolumn{2}{|c|}{$y^{2}$} & \multirow[b]{2}{*}{$\begin{array}{l}\text { Média } \\
\text { Mean }\end{array}$} & \multirow[t]{2}{*}{ CV (\%) } \\
\hline & $\begin{array}{c}\text { Baixo } \\
\text { Low }\end{array}$ & $\begin{array}{l}\text { Alto } \\
\text { High }\end{array}$ & & \\
\hline $\begin{array}{l}\text { Baixo } \\
\text { Low }\end{array}$ & $66,9 \mathrm{Aa}$ & $68,8 \mathrm{Aa}$ & 67,9 & \\
\hline $\begin{array}{l}\text { Alto } \\
\text { High }\end{array}$ & $59,7 \mathrm{Bb}$ & $67,6 \mathrm{Aa}$ & 63,6 & \\
\hline $\begin{array}{l}\text { Média } \\
\text { Mean }\end{array}$ & 63,3 & 68,2 & - & 3,29 \\
\hline
\end{tabular}

Médias seguidas de letras distintas, minúsculas (linha) e maiúscula (coluna), diferem $(P<0,05)$ pelo teste $F$.

${ }^{1}$ GPC - ganho diário estimado de peso corporal: alto (1 kg/animal) e baixo $(0,5 \mathrm{~kg} / \mathrm{animal})$.

2 y - potencial estimado de fermentação microbiana: alto (11 g PB microbiana/MJ EM fermentável) e baixo (9,5 g PB microbiana/MJ EM fermentável).

Means followed by different letters, small (row) and capital (column), are different $(P<0.05)$ by F test.

${ }^{1}$ BWG - estimated daily body weight gain: high (1 kg/animal) and low (0.5 kg/animal).

2 Estimated potential of microbial fermentation: high (11 g microbial CP/MJ fermentable ME and low (9.5 g microbial CP/MJ fermentable ME).

baixo GPC. Observou-se ainda intensa degradação desta fração, o que contribuiu para que a estimativa de "b" ficasse acima dos valores descritos na literatura.

Martins et al. (1999) obtiveram valores médios para os parâmetros “a”, “b” e “c” de 47,5\%; 50,4\% e 0,109\%/hora, respectivamente, o que determinou DE5 da PB do farelo de algodão de 81,4\%. Valadares Filho (1995) relacionou valores médios de 32,6\%; 57,3\%; 0,047/hora e 54,3\% para “a”, “b” e “c” e DE5, respectivamente. O AFRC (1993) adotou os valores de 36,0\%; 60,0\%; 0,06\%/hora e 59,2\% para “a”, “b” e “c” e DE5, respectivamente.

Houve interação entre as dietas para nível de GPC e o tempo de incubação do alimento, portanto, a degradação das frações MS e MO diferiu à medida que transcorreu o tempo de incubação (Tabela 12).

Apesar da complexa alternância quanto à degradação de ambas as frações nutritivas, os animais alimentados com dietas para baixo ganho de peso apresentaram ao longo do tempo médias mais baixas $(\mathrm{P}<0,05)$ no tempo de 12 horas, o que não ocorreu às 48 horas no caso da MS. Em ambas as dietas, a degradação dos nutrientes no tempo de incubação de 3 horas foi semelhante $(\mathrm{P}>0,05)$.

\section{Conclusões}

Considerando os aspectos ruminais, não se justifica o balanceamento de dietas visando ganho de peso corporal de 0,5 ou 1,0 kg/animal/dia para tourinhos em terminação alimentados com feno de capim-marandu. Nesse caso, também não se justifica que as dietas sejam balanceadas 
Tabela 12 - Variação no tempo da degradação (em \%) da MS e MO do farelo de algodão nas diferentes taxas de ganho diário de peso corporal (GPC)

Table 12 - Variation in the time of the degradation (in \%) of DM and OM of the cottonseed meal on the different rates of body weight daily gain (BWG)

\begin{tabular}{llccc}
\hline Fração & & \multicolumn{3}{c}{$\begin{array}{c}\text { Tempo (h) } \\
\text { Time (h) }\end{array}$} \\
\cline { 3 - 5 } & & 3 & 12 & 48 \\
\hline \multirow{2}{*}{ MS } & Baixo GPC & 28,6 & $45,4 \mathrm{~b}$ & $76,3 \mathrm{a}$ \\
$D M$ & $\begin{array}{l}\text { Low BWG } \\
\text { Alto GPC }\end{array}$ & 30,2 & $49,6 \mathrm{a}$ & $73,3 \mathrm{~b}$ \\
& High BWG & & & \\
\hline \multirow{3}{*}{ MO } & Baixo GPC & 27,7 & $43,8 \mathrm{~b}$ & 75,2 \\
OM & $\begin{array}{l}\text { Low BWG } \\
\text { Alto GPC }\end{array}$ & 29,2 & $48,1 \mathrm{a}$ & 72,2 \\
& High BWG & & & \\
\hline
\end{tabular}

Médias seguidas de letras distintas na coluna, para cada nutriente, diferem $(\mathrm{P}<0,05)$ pelo teste $\mathrm{F}$.

Means followed by different letters within a column, for each nutrient, are different $(P<0.05)$ by F test.

para potenciais de fermentação microbiana entre 9,5 e $11 \mathrm{~g}$ de proteína bruta microbiana/MJ de energia metabolizável fermentável. No entanto, esses diferentes potenciais de fermentação microbiana alteraram a degradabilidade das frações nutritivas dos ingredientes protéicos da dieta, farelo de soja e de algodão. A degradabilidade dos nutrientes do volumoso e dos ingredientes protéicos também foi influenciada pelas dietas formuladas para diferentes ganhos de peso.

\section{Literatura Citada}

AGRICULTURAL AND FOOD RESEARCH COUNCIL - AFRC. Energy and protein requirements of ruminants. Wallingford: CAB International, 1993. 159p.

AGRICULTURAL RESEARCH COUNCIL - ARC. The nutrient requirements of ruminant livestock. Farnham Royal, 1984. 45p. (suppl. 1).

ASSOCIATION OF OFFICIAL ANALYTICAL CHEMISTS AOAC. Official methods of analysis. 16.ed. Washington, 1995. v.1, p.1-30.

BARBOSA, N.G.S.; LANA, R.P.; JHAM, G.N. et al. Consumo e fermentação ruminal de proteínas em função de suplementação alimentar energética e protéica em novilhos. Revista Brasileira de Zootecnia, v.30, n.5, p.1558-1565, 2001.

BRITO, R.M. Estudo da fermentação ruminal em bovinos alimentados com dietas ajustadas por diferentes sistemas de nutrição. Jaboticabal: Universidade Estadual Paulista, 2000. 96p. Dissertação (Mestrado em Zootecnia) - Universidade Estadual Paulista, 2000.

BRITO, R.M.; SAMPAIO, A.A.M.; FERNANDES, A.R.M. et al. Digestibilidades parciais e total de dietas com feno de capimmarandu e concentrado, balanceadas para diferentes níveis de produção. Revista Brasileira de Zootecnia, v.35, n.4, p.1796-1804, 2006 (supl.).
BÜRGUER, P.J.; PEREIRA, J.C.; COELHO DA SILVA, J.F. et al. Taxas de passagem e cinética da degradação e cinética da degradação ruminal em bezerros holandeses alimentados com dietas contendo diferentes níveis de concentrado. Revista Brasileira de Zootecnia, v.29, n.1, p.225-235, 2000.

DIAS, H.L.V.; VALADARES FILHO, S.C.; COELHO DA SILVA, J.F. et al. Eficiência da síntese microbiana, $\mathrm{pH}$ e concentrações ruminais de amônia em novilhos F1 Limousin-Nelore alimentados com dietas contendo cinco níveis de concentrado. Revista Brasileira de Zootecnia, v.29, n.2, p.555-565, 2000.

ERWIN, E.S.; MARCO, G.J.; EMERY, E.M. Volatile fatty acid analyses of blood and rumen fluid by gas chromatography. Journal of Dairy Science, v.44, n.9, p.1768-1771, 1961.

FENNER, H. Methods for determining total volatile bases in rumen fluid by steam destillation. Journal of Dairy Science, v.48, p.249, 1965.

FOX, D.G.; SNIFFEN, C.J.; O’CONNOR, J.D. et al. A Net Carbohydrate and Protein System for evaluating cattle diets. III - Cattle requirements and diet adequacy. Journal of Animal Science, v.70, n.10, p.3578-3596, 1992.

FU, C.J.; FELTON, E.E.; LEHMKUHLEI, J.W. et al. Ruminal peptide concentration to optimize microbial growth and efficiency. Journal of Animal Science, v.79, n.5, p.13051312, 2001.

ÍTAVO, L.C.V.; VALADARES FILHO, S.C.; SILVA, F.F. et al. Consumo, degradabilidade ruminal e digestibilidade aparente de fenos de gramíneas do gênero Cynodon e rações concentradas utilizando indicadores internos. Revista Brasileira de Zootecnia, v.31, n.2, p.1024-1032, 2002a (supl.).

ÍTAVO, L.C.V.; VALADARES FILHO, S.C.; SILVA, F.F. et al. Níveis de concentrado e proteína bruta na dieta de bovinos Nelore nas fases de recria e terminação:consumo e digestibilidade. Revista Brasileira de Zootecnia, v.31, n.2, p.1033-1041, 2002b (supl.).

ÍTAVO, L.C.V.; VALADARES FILHO, S.C.; SILVA, F.F. et al. Consumo e digestibilidade aparentes totais e parciais de nutrientes em novilhos alimentados com dietas contendo vários níveis de concentrado. Revista Brasileira de Zootecnia, v.31, n.3, p.1543-1552, 2002c (supl.).

ÍTAVO, L.C.V.; VALADARES FILHO, S.C.; SILVA, F.F. et al. Produção microbiana e parâmetros ruminais de novilhos alimentados com dietas contendo vários níveis de concentrado. Revista Brasileira de Zootecnia, v.31, n.3, p.1553-1561, 2002d (supl.).

ÍTAVO, L.C.V.; VALADARES FILHO, S.C.; SILVA, F.F. et al. Comparação de indicadores e metodologia de coleta para estimativas de produção fecal e fluxo de digesta em bovinos. Revista Brasileira de Zootecnia, v.31, n.4, p.1833-1839, 2002e.

LEÃO, M.I.; COELHO DA SILVA, J.F. Técnica de fistulação de abomaso em bezerros. In: REUNIÃO ANUAL DA SOCIEDADE BRASILEIRA DE ZOOTECNIA, 17., 1980, Fortaleza. Anais... Fortaleza: Sociedade Brasileira de Zootecnia, 1980. p.37.

MARTINS, A.S.; ZEOULA, L.M.; PRADO, I.N. Degradabilidade ruminal in situ da matéria seca e proteína bruta das silagens de milho e sorgo e de alguns alimentos concentrados. Revista Brasileira de Zootecnia, v.28, n.3, p.1109-1117, 1999.

MEHREZ, A.Z.; ØRSKOV, E.R. A study of the artificial fibre bag technique for determining the digestibility of feed in rumen. Journal of Agricultural Science, v.88, n.3, p.654-660, 1977.

NATIONAL RESEARCH COUNCIL - NRC. Nutrient requirements of beef cattle. Washington: National Academy Press, 1984. 90p.

NOCEK, J.E. In situ and other methods to estimate ruminal protein and energy digestibility: a review. Journal of Agricultural Science, v.71, n.6, p.2051-2069, 1988.

ØRSKOV, E.R.; McDONALD, I. The estimation of protein degradability in the rumen from incubation measurements weighted according to rate of passage. Journal of Agricultural Science, v.92, p.499-503, 1979. 
PAULINO, M.F.; DETMANN, E.; VALADARES FILHO, S.C. et al. Soja grão e caroço de algodão em suplementos múltiplos para terminação de bovinos mestiços em pastejo. Revista Brasileira de Zootecnia, v.31, n.1, p.484-491, 2002 (supl.).

QUEIROZ A.C.; BARBOSA, M.A.; RESENDE, F.D. Suplementação da palhada de milho na alimentação de bovinos. 2. Concentração de amônia ruminal e pH ruminal. Revista Brasileira de Zootecnia, v.27, n.2, p.390-396, 1998.

SAMPAIO, I.B.M. Experimental designs and modelling techniques in the study of roughage degradation in rumen and growth of ruminants. Reading: University of Reading, 1988. 227p. Thesis (Doctor of Philosophy) University of Reading, 1988.

SAMPAIO, I.B.M. Estatística aplicada à experimentação animal. Belo Horizonte: Fundação de Ensino e Pesquisa em Medicina Veterinária e Zootecnia, 1998. 221p.

SATTER, S.D.; SLYTER, L.L. Effects of ammonia concentration on rumen microbial protein production "in vitro". British Journal of Nutrition, v.32, p.245, 1974.

VALADARES FILHO, S.C. Eficiência de síntese de proteína microbiana, degradação ruminal e digestibilidade intestinal da proteína bruta em bovinos. In: SIMPÓSIO INTERNACIONAL SOBRE EXIGÊNCIAS NUTRICIONAIS DE RUMINANTES, 1., 1995, Viçosa, MG. Anais... Viçosa, MG: Universidade Federal de Viçosa, 1995. p.355-388.
Van SOEST, P.J. Nutritional ecology of the ruminants. Corvalis: OB Books Inc., 1982. 374p.

Van SOEST, P.J.; ROBERTSON, J.B.; LEWIS, B.A. Methods of dietary fiber, neutral detergent fiber, and nonstarch polysaccharides in relation to animal nutrition. Journal of Dairy Science, v.74, n.10, p.3583-3597, 1991.

VELOSO, C.M.; RODRIGUEZ, N.M.; SAMPAIO, I.B.M. et al. pH e amônia ruminais, relação folhas:hastes e degradabilidade ruminal da fibra e de forrageiras tropicais. Revista Brasileira de Zootecnia, v.29, n.3, p.871-879, 2000

VILELA, G.L.; VALADARES FILHO, S.C.; SILVA, J.F.C. et al. Degradabilidades "in situ" da matéria seca e da proteína bruta e proteína efetivamente degradada no rúmen de vários alimentos. Revista da Sociedade Brasileira de Zootecnia, v.23, n.3, p.342-351, 1994. 